\title{
Cerebral Cavernous Malformations, Developmental Venous Anomaly, and Its Coexistence: A Review
}

\author{
Pretty Sara Idiculla ${ }^{a}$ Dhineshreddy Gurala ${ }^{b}$ Jobin Philipose ${ }^{b}$ \\ Kartikeya Rajdev ${ }^{c}$ Prateek Patibandla ${ }^{d}$ \\ aUniversity of Missouri Health Care, Columbia, MO, USA; bStaten Island University Hospital, Northwell Health, \\ Staten Island, NY, USA; ${ }^{c}$ University of Nebraska Medical Center, Omaha, NE, USA; ${ }^{d}$ Tower Health Reading Hospital, \\ West Reading, PA, USA
}

\section{Keywords}

Cerebral cavernous malformations · Developmental venous abnormality $\cdot$ Mixed cerebral vascular malformations

\begin{abstract}
Background: Cerebral cavernous malformations (CCMs) are intracranial vascular malformations that can exist as a single lesion or mixed vascular lesions. The most common mixed form is the coexistence of CCM with an associated developmental venous anomaly (DVA). In this paper, we aim to give a comprehensive review of CCM, DVA, and their coexistence as mixed lesions. A PubMed search using the keywords "Cerebral cavernous malformations, Developmental venous anomaly, Mixed Cerebral cavernous malformations with Developmental venous anomaly" was done. All studies in the English language in the past 10 years were analyzed descriptively for this review. Summary: The search yielded 1,249 results for "Cerebral cavernous malformations," 271 results for "Developmental venous anomaly," and 5 results for "Mixed Cerebral cavernous malformations with Developmental venous anomaly." DVA is the most common intracranial vascular malformation, followed by CCM. CCM can have a wide array of clinical presentations like hemorrhage, seizures, or
\end{abstract}

focal neurological deficits or can also be an incidental finding on brain imaging. DVAs are benign lesions by nature; however, venous infarction can occur in a few patients due to acute thrombosis. Mixed CCM with DVA has a higher risk of hemorrhage. CCMs are angiographically occult lesion, and cerebral digital subtraction angiography is the gold standard for the diagnosis of DVA. Mixed lesions, on the other hand, are best diagnosed with magnetic resonance imaging, which has also been effective in detecting specific abnormalities. Asymptomatic lesions are treated through a conservative approach, while clinically symptomatic lesions need surgical management. Conclusion: Individual CCM or DVA lesions have a benign course; however, when they coexist in the same individual, the hemorrhagic risk is increased, which prompts for rapid diagnosis and treatment.

(c) 2020 S. Karger AG, Basel

\section{Introduction}

Cerebral cavernous malformations (CCM) are intracranial vascular malformations that can exist as a single or mixed vascular lesion. The most common mixed form is the coexistence of CCM with an associated develop- karger@karger.com www.karger.com/ene

(c) 2020 S. Karger AG, Base

Karger"
Pretty Sara Idiculla

University of Missouri Health Care, Columbia, MO, USA 202 Grasmere Drive

Staten Island, NY 10305 (USA)

sarahidiculla.psi@gmail.com 
Fig. 1. Intracranial vascular malforma-

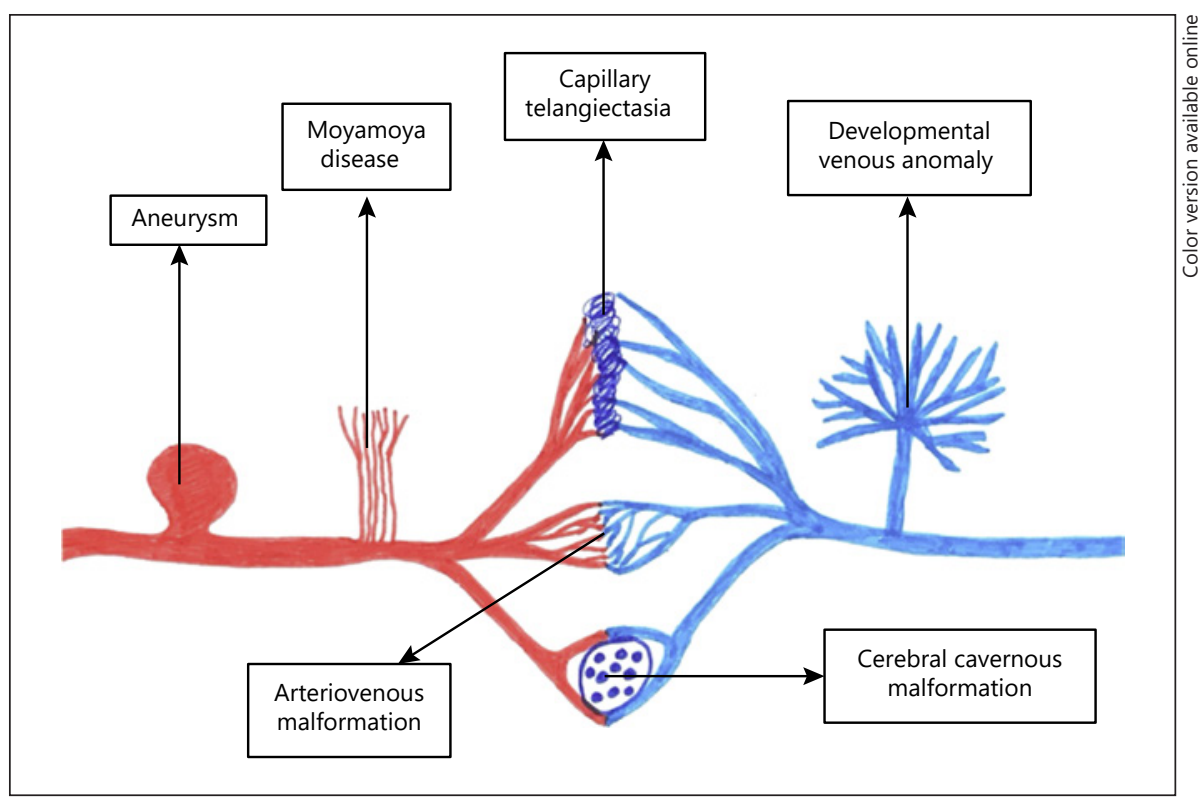

mental venous anomaly (DVA). These lesions follow a benign course as individual lesions but have a high risk of hemorrhage when they occur together. In this paper, we discuss in detail the topic of CCM, DVA, and their occurrence as a mixed vascular malformation.

\section{Intracranial Vascular Malformations}

Intracranial or cerebral vascular malformations are a group of vascular lesions with varying hemodynamic or structural properties (Fig. 1). Aneurysms - abnormal saccular outpouchings of the cerebral arteries [1]. Moyamoya disease - chronic occlusive cerebrovascular disease resulting in progressive stenosis of the internal carotid artery and its branches [2]. Capillary telangiectasia - dilated thinwalled capillaries due to the absence of smooth muscle or elastic fibers [3]. Arteriovenous malformations - clusters of abnormal arteries and veins with an increased risk of intracranial bleed, more common in young adults [4]. DVAs most commonly encountered malformation involving the intracranial venous system, which are also known as venous angioma, cerebral venous medullary malformation, or cerebral venous malformation [5]. CCM - vascular spaces of varying sizes, lined by a single layer of endothelin with no distinct features of arteries or veins [6]. Mixed vascular malformation - coexistence of vascular malformations and the most commonly encountered form is a CCM that occurs in association with a DVA [7].

Cerebral Cavernous Malformations and

Developmental Venous Anomaly

\section{Cerebral Cavernous Malformations}

CCMs are also called as cavernous angioma, cavernous hemangioma, or cavernoma.

\section{Genetics}

Hereditary or familial CCM - this constitute about $20 \%$ of all cavernomas in patients, has a positive family history, and it commonly occurs as multiple lesions. It occurs from autosomal dominant mutation of 3 genes CCM1, CCM2, and CCM3 [8] (Table 1). In most cases, it can be a nonsense, frameshift, or splice site mutation, resulting in a nonfunctional protein product. In some cases, there can be a deletion or duplication of multiple exons or the entire gene [9]. Sporadic CCM - sporadic cavernomas are less common and occur as single lesions. They are usually asymptomatic and may occur in association with a DVA [10].

\section{Epidemiology}

CCMs have an incidence of $<1 \%$, an annual hemorrhage risk of up to $3 \%$, and a rebleed risk of $4.5-23 \%$ per year [12]. They are the second most common form of intravascular malformations, after DVA. The malformations can be present in any age group, though it is found to be more common during the third decade of life [10]. A prospective imaging study done in the Mayo Clinic involving 4,721 individuals of ages between 50 and 89 years found an overall prevalence of $0.46 \%$, with a slightly high- 
Table 1. Familial CCM genes [11]

\begin{tabular}{llll}
\hline Gene & Gene locus & Chromosome & Function \\
\hline KRIT1 & CCM1 & $7 \mathrm{q}$ & $\begin{array}{l}\text { Regulate heart and vessel formation } \\
\text { Regulate angiogenesis }\end{array}$ \\
\hline CCM2 & CCM2 & $7 \mathrm{p}$ & $\begin{array}{l}\text { Regulate heart and vessel formation } \\
\text { Maintain vessel integrity } \\
\text { Stabilize endothelial cell junction }\end{array}$ \\
\hline PDCD10 & CCM 3 & $\begin{array}{l}\text { Stimulate cell proliferation } \\
\text { Regulate apoptosis } \\
\text { Regulate heart development } \\
\text { Regulate angiogenesis, vasculogenesis, and hematopoiesis }\end{array}$ \\
\hline CCM, cerebral cavernous malformation. &
\end{tabular}

er prevalence among men than among women [13]. The overall prevalence of familial CCM is about 1:3,300$1: 3,800$, and the occurrence of symptomatic hereditary mutations is approximately 1:5,400-1:6,200 [14]. There are studies that suggest a higher occurrence of familial CCMs in patients with a Hispanic ancestry of Mexican or southwest US-American descent $[15,16]$.

\section{Pathology}

CCMs are single-layer endothelin-lined vascular spaces without intervening brain parenchymal tissue within them [17]. There is low pressure and slow flow of blood within the lesion, which results in thrombus formation, followed by its organization, and this occurs in a repetitive fashion. These features are grossly visualized as the characteristic "mulberry appearance" [18]. There is insufficiency of the tight and adherens junctions of the endothelial cells, resulting in leaking and a dysfunctional blood-brain barrier [14].

\section{Clinical Presentation}

CCMs can have varied presentations depending on the location of the lesion. They can be supratentorial, which affects the cerebral cortex, and infratentorial, affecting the brainstem or the cerebellum; however, most of them are supratentorial lesions [19]. When these lesions become symptomatic, it can have a wide array of clinical presentation that includes seizures, hemorrhage, headache, and focal neurological deficits [20]. Supratentorial lesions have been found to present more commonly with seizures, whereas infratentorial malformations present with focal neurological deficits [21]. There are studies that try to explain the natural course of hemorrhage oc- curring in patients with CCM $[22,23]$. Gross and Du [24] summarized the risk factors for hemorrhage in these patients, which included prior hemorrhage from a cerebral cavernous angioma, female sex, and brainstem location of the lesion. Cavernous angiomas are a rare cause of an isolated non-aneurysmal SAH, and very few cases have been reported [25].

\section{Diagnosis}

Imaging Studies

CCM diagnosis is particularly challenging to the practicing physicians because they tend to be angiographically occult due to the slow blood flow through them. Due to their increased potential of recurrent bleeding, early detection and prompt management are demanded [9].

\section{CT Scans}

CT scans can detect lesions that are complicated by hemorrhage or calcification but lack the sensitivity and specificity to detect smaller lesions; hence, it is not the primary modality for diagnosis of these lesions [26].

\section{Magnetic Resonance Imaging}

MRI has been found to show a higher specificity to detect both symptomatic and asymptomatic lesions as well as cavernomas located in the posterior cranial fossa or the brainstem [27, 28]. Based on the MRI images, cavernous angiomas can be classified into 4 types (Table 2). The MRI findings of cavernomas can also be seen in other disease conditions like hemorrhagic neoplasms or metastasis, calcification of neoplasms, cryptic vascular malformations, oligodendrogliomas, and pleomorphic xanthoastrocytomas [29]. 
Table 2. Classification of CCM based on MRI appearance [30]

\begin{tabular}{|c|c|c|c|c|}
\hline Types & $\mathrm{T} 1$ sequence & $\mathrm{T} 2$ sequence & GRE sequence & Cause \\
\hline Type 1 & Hyperintensity & Hyperintensity & - & Subacute hemorrhage \\
\hline Type 2 & $\begin{array}{l}\text { Classic cavernous angioma } \\
\text { "popcorn" lesions that have an } \\
\text { increased risk of recurrent } \\
\text { symptoms, appearing as reticulated, } \\
\text { mixed-signal core due to loculated } \\
\text { areas of hemorrhage }\end{array}$ & $\begin{array}{l}\text { Classic cavernous angioma "popcorn" } \\
\text { lesions that have an increased risk of } \\
\text { recurrent symptoms, appearing as } \\
\text {,reticulated, mixed-signal core due to } \\
\text { loculated areas of hemorrhage and a } \\
\text { surrounding hypointense rim }\end{array}$ & - & $\begin{array}{l}\text { The surrounding } \\
\text { hypointense rim occurs } \\
\text { from gliosis and } \\
\text { hemosiderin-stained brain }\end{array}$ \\
\hline $\begin{array}{l}\text { Type 3: } \\
\text { commonly asymptomatic and } \\
\text { found in familial forms of } \\
\text { cavernous angiomas }\end{array}$ & Hypo- or isointense & Hypointense & $\begin{array}{l}\text { Markedly } \\
\text { hypointense }\end{array}$ & $\begin{array}{l}\text { Changes are } \\
\text { characteristics of chronic } \\
\text { resolve hemorrhage with } \\
\text { hemosiderin-staining } \\
\text { within the lesion }\end{array}$ \\
\hline $\begin{array}{l}\text { Type } 4 \text { : } \\
\text { minute cavernous malformation } \\
\text { similar in appearance to } \\
\text { telangiectasia and produce acute } \\
\text { progressive symptoms }\end{array}$ & e & - & $\begin{array}{l}\text { Small, punctate } \\
\text { hypointense foci }\end{array}$ & - \\
\hline
\end{tabular}

CCM, cerebral cavernous malformation; GRE, gradient recall echo.

Gradient Recall Echo MRI

Gradient recall echo (GRE) MRI is used for the accurate detection of CCM due to the characteristic hypointensity produced due to detection of hemosiderin-filled brain parenchyma [31]. Microhemorrhages seen on GRE MRI sequences are also a finding in elderly patients with hypertension and cerebral amyloid angiopathy [32].

\section{Susceptibility Weighted MRI}

Susceptibility-weighted (SW) MRI is more precise in detecting vascular malformations due to its high sensitivity to deoxyhemoglobin and iron content [33]. This is the only imaging method that can detect capillary telangiectasias and cavernomas that are nonhemorrhagic [34]. A study in 2008 has shown that the detection rate of familial CCMs by SW MRI was 1.7 times higher than that by T2/ GRE MRI [35]. Though it can detect multifocal familial CCMs, it has not been proven superior to T2/GRE MRI. SW MRI is also not sensitive in detecting sporadic or solitary CCMs and CCM lesion associated with DVA and differentiating small venous structures from microhemorrhage and thrombosis [36].

\section{Diffusion Tensor MRI and Functional MRI}

Diffusion tensor MRI and functional MRI are used to visualize the lesions and surrounding brain tissue intraoperatively to improve the outcome of the surgery. Diffu- sion tensor MRI helps identify and avoid resection of areas like the white matter tracts, helping reduce the surgery-associated morbidity. Functional MRI helps assess cerebral blood flow to parts of the brain in association with activity, which helps assess the essential areas, thus aiding surgical resection of CCM [30].

\section{Genetic Studies}

Familial CCM patients should undergo a direct genetic sequencing of CCM1-3, followed by a deletion or duplication analysis. This has shown a detection rate of approximately $75 \%$ of all cases with multiple lesions [9].

\section{Treatment}

One study has described an algorithm summarizing the treatment options for cavernous angioma when it is diagnosed on a brain MRI: If the lesion was diagnosed incidentally and has no clinical manifestations, it only requires conservative management irrespective of the location and yearly MRIs to assess the growth of the lesions. If the lesion has a severe clinical presentation, surgical management with either microsurgical resection or stereotactic radiosurgery was suggested [31].

\section{Conservative Management}

Depending on the location of the CCM and the age of the patient, asymptomatic lesions can be treated by regu- 
Table 3. Management guidelines for CRE [44]

\begin{tabular}{ll}
\hline Situation & Guideline \\
\hline $\begin{array}{l}\text { Incidental CCM or CCM with intracranial hemorrhage or } \\
\text { focal neurologic deficits }\end{array}$ & No prophylactic antiepileptic therapy \\
\hline CCM with new-onset single or multiple seizures & Antiepileptic therapy is indicated \\
\hline CRE patients who are symptom-free on antiepileptics & Regular follow-up with a seizure specialist \\
\hline CRE patients with persistent seizures & Epilepsy surgery after complete preoperative evaluation \\
\hline CRE patients with multiple cavernomas & Video electroencephalogram monitoring is mandatory \\
\hline CRE patients with dual or triple pathology & $\begin{array}{l}\text { Invasive evaluation to localize and identify the extent of epileptogenic } \\
\text { zone may be considered }\end{array}$ \\
\hline
\end{tabular}

CRE, CCM-related epilepsy; CCM, cerebral cavernous malformation.

lar follow-up [37]. This is also preferred if the patient has increased risk associated with surgery. There are no set guidelines currently available for determining the frequency of imaging for follow-up [38].

\section{Surgical Management}

Surgical resection is the most preferred form of intervention for CCM. Selection of a procedure depends on the location and severity at the presentation, which includes intractable seizures, progressive neurological deterioration, one severe hemorrhage in a non-eloquent region of the brain, or at least 2 severe hemorrhages in eloquent regions of the brain [31]. A complete resection of the lesion is mandatory due to the increased risk of hemorrhage and seizures due to remnant tissue [38]. The procedure can also be complicated by occurrence of gliosis, calcification, and hyaline degeneration following resection of the lesion [39]. The removal of hemosiderin ring should be done in patients who undergo seizure surgery. Due to an increased risk of hemorrhage from remnants, an MRI is recommended within $72 \mathrm{~h}$ post-surgery [40]. Microsurgical resection that is done more using intraoperative imaging helps reduce the risk of surgical complications, making it a preferred modality for the treatment of cavernous angiomas [41].

\section{Stereotactic Radiosurgery}

When cavernous angioma is inoperable or carries with it a higher surgical risk, stereotactic radiosurgery may be used as an option for treating the lesion, though there is controversy about its effectiveness and concern about complications like radiation-induced genesis of new cavernomas [42]. Niranjan and Lunsford [43] proposed a guideline to select patients for stereotactic radiosurgery. It includes factors like age of the individual, location of the lesion, the risk of hemorrhage, the risk associated with surgery, and the history of previous hemorrhages.

\section{Medical Therapy}

There are no medications currently useful for treating CCM. The medications used are for treatment of clinical symptoms like seizures. Rosenow et al. [44] proposed a guideline for diagnostic evaluation and therapy for patients with seizures that occur in association with CCM (Table 3). Conservative management is preferred over surgery in these patients due to the low risk of seizure occurrence in patients with cavernomas. Headache is the most common symptom of CCMs. Standard migraine therapy is considered for those patients who meet the criteria for migraine [9]. Though some studies have shown a likely safety of antiplatelet and antithrombotic medications in lowering the bleeding risk in preexisting CCM, these studies have limitations $[45,46]$.

\section{Developmental Venous Anomaly}

DVAs are the most frequently encountered intracranial malformations on imaging.

\section{Epidemiology}

DVAs have an incidence rate of $>2 \%$ based on both autopsy and imaging studies [47]. The hemorrhagic risk of DVA is considered $<0.7 \%$ and has been seen more in patients having lesions in the posterior fossa or in pregnant patients [48]. 
Table 4. Pathophysiology of symptomatic DVA [53]

\begin{tabular}{|c|c|c|}
\hline Mechanism & Explanation & Clinical presentation \\
\hline Mechanical & When a part of the DVA compressed on intracranial structures & $\begin{array}{l}\text { Obstructive hydrocephalus } \\
\text { Neurovascular compression }\end{array}$ \\
\hline \multirow[t]{5}{*}{ Flow-related } & $\begin{array}{l}\text { When there is a loss of balance in the inflow (increased) and } \\
\text { outflow (decreased) of blood in the DVA system, resulting in } \\
\text { raised pressure }\end{array}$ & $\begin{array}{l}\text { Inflow misbalance can result in hemorrhage and } \\
\text { venous infarction resulting in headache, focal } \\
\text { neurological deficits, seizures, coma }\end{array}$ \\
\hline & $\begin{array}{l}\text { Increased inflow occurs as a result of microshunt into the DVA } \\
\text { or due to an AVM utilizing the DVA as a drainage route }\end{array}$ & Outflow misbalance: \\
\hline & Decreased outflow can occur due to the following: & $\begin{array}{l}\text { Anatomical causes - headache, seizure, altered } \\
\text { mental status }\end{array}$ \\
\hline & $\begin{array}{l}\text { Anatomical causes - thrombosis of the DVA, stenosis or } \\
\text { occlusion of the collecting vein, or the draining sinus }\end{array}$ & Functional cause - venous hypertension \\
\hline & $\begin{array}{l}\text { Functional cause - a distant shunt/AVM resulting in a remote } \\
\text { arterial overload to the venous system }\end{array}$ & \\
\hline $\begin{array}{l}\text { Spontaneous/ } \\
\text { idiopathic }\end{array}$ & Symptomatic cases with no identifiable mechanism & \\
\hline
\end{tabular}

DVA, developmental venous anomaly; AVM, arteriovenous malformations.

\section{Etiology}

The exact etiology of DVA is not known and is thought to develop as a compensation to the absence of normal vessels resulting from hypoplasia, aplasia, or an early occlusion of the developing veins [49].

\section{Pathology}

DVAs are radial clusters of dilated centripetally draining medullary veins, typically called the "caput medusa" that converge into a common collecting vein, which drains the normal brain parenchyma [50].

\section{Clinical Presentation}

DVAs were thought to be very rare lesions in the past, and with diagnostic MRI being used more, the number of cases that are diagnosed has also increased. DVAs are benign and asymptomatic in most scenarios. Acute thrombosis of the collecting vein may result in venous infarction of the surrounding brain parenchyma [51, 52]. The pathophysiological mechanisms underlying symptomatic DVA are explained in Table 4.

\section{Diagnosis}

DVAs can be diagnosed with a CT or an MRI and digital subtraction angiography, which is the gold standard for diagnosis as it helps study the flow of blood through the various channels of a DVA [50]. Regardless of the imaging modality that is used, DVA diagnosis depends on identifying the area of caput medusa that drains into a common collecting vein. In a CT without contrast, the collecting vein appears isodense and the acute thrombosis becomes hyperdense. It also helps in detecting calcifications, white matter lesions, atrophy, and hemorrhage associated with DVA [50]. Non-contrast MRI may show phase-shift artifact and flow voids caused by the larger radical venous branches and the collecting vein [54]. Contrast-enhanced CT or gadolinium administration with MRI has been found to demonstrate DVAs by showing marked enhancement of the radial veins and the main collecting vessel [55]. GRE or SW MRI helps in detecting any acute parenchymal bleed or intravascular thrombosis [51].

\section{Treatment}

DVAs that are asymptomatic or found incidentally are not treated. Though no large-scale controlled studies exist to support use of anticoagulants, it has been recommended in symptomatic, thrombosed venous angioma after extensive evaluation of affected patients for additional hemorrhagic risks [48]. Surgical excision of a DVA can result in venous congestion, leading to severe venous infarction thus favoring conservative man- 


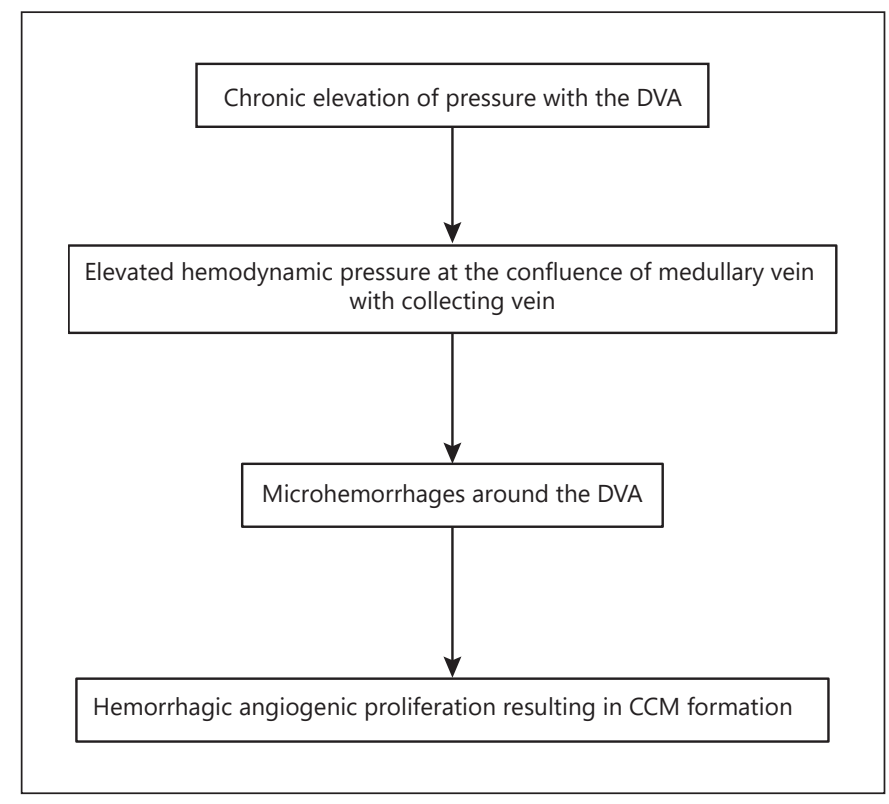

Fig. 2. Pathogenesis of a mixed CCM and DVA $[61,62]$. CCM, cerebral cavernous malformation; DVA, developmental venous anomaly.

agement. Surgery is indicated in patients who present with a massive intracerebral hematoma and since they drain normal brain tissue radiosurgery is contraindicated [56].

\section{Mixed CCMs with DVA}

The coexistence of CCM and DVA is the most common form of mixed intracranial vascular malformation.

\section{Epidemiology}

A retrospective study of parenchymal abnormalities associated with DVA showed that approximately $13 \%$ of patients who had a cavernoma had an associated venous anomaly [57]. Hemorrhagic complications that occur in cases with a coexisting cavernoma with DVA is higher than an isolated cavernoma [58]. Mixed vascular malformations are currently being diagnosed at a higher rate, and there are reports on literature that suggest a causal relationship between a CCM and a DVA $[59,60]$.

\section{Pathophysiology}

DVAs are considered to play the evolutional role in the development and growth of CCM. The probable pathogenesis of this development is explained in Figure 2.

\section{Diagnosis}

The use of contrast-enhanced MRI has shown to increase the detection of cavernous angiomas with coexistent DVAs, and the use of T2-weighted gradient echo MRI or SW images may help to identify these combined lesions $[63,64]$.

\section{Treatment}

Surgical excision is a commonly accepted treatment option for patients with symptomatic cavernous angio$\mathrm{ma}$, and when associated with a DVA, the venous anomaly should be spared due to the potential danger of devastating venous infarction. Treatment of these lesions should be decided by gauging risks versus benefit of surgery over the natural course of these lesions [65].

\section{Conclusions}

CCMs and DVAs are intracranial vascular malformations whose natural history is still not well understood. Individually, these lesions have a benign natural course; however, when they coexist in the same individual, the hemorrhagic risk is increased, which prompts for rapid diagnosis and treatment. An MRI is helpful in the detection of individual and mixed vascular malformations. Conservative management for asymptomatic lesions and surgery for clinically symptomatic lesions appear to be a satisfying approach for the treatment of these CCM. Surgery is avoided in DVA patients due to the risk of thrombosis and infarction. In mixed lesions, if indicated, only the cavernoma is surgically resected and the DVA is left untouched.

\section{Future Research}

Further studies are also necessary to understand more about the following: The natural course of CCMs, DVAs, and mixed malformations. Assessment and screening of patients presenting with hemorrhage from single or multiple lesions. Guidelines to follow for the diagnosis of individual and mixed vascular malformations as well as the imaging modalities that can be used for rapid detection of such lesions. Comparison studies to assess the efficacy of the different imaging options that are available. Determine the efficacy of medical treatment options in place of surgery. 


\section{Conflict of Interest Statement}

The authors declare that they have no conflicts of interests.

\section{Author Contributions}

All authors have been involved in the preparation of the manuscript. All authors have read and approved the manuscript. The corresponding author has full access to data and has the right to publish this paper.

\section{References}

1 Brisman JL, Song JK, Newell DW. Cerebral aneurysms. N Engl J Med. 2006;355(9):92839.

2 Huang S, Guo ZN, Shi M, Yang Y, Rao M. Etiology and pathogenesis of Moyamoya disease: an update on disease prevalence. Int J Stroke. 2017;12(3):246-53.

3 Abla A, Wait SD, Uschold T, Lekovic GP, Spetzler RF. Developmental venous anomaly, cavernous malformation, and capillary telangiectasia: spectrum of a single disease. Acta Neurochir. 2008 May;150(5):487-9; discussion 489.

4 Can A, Gross BA, Du R. The natural history of cerebral arteriovenous malformations. Handb Clin Neurol. 2017;143:15-24.

5 Nabavizadeh SA, Mamourian AC, Vossough A, Loevner LA, Hurst R. The many faces of cerebral developmental venous anomaly and its mimicks: spectrum of imaging findings. J Neuroimaging. 2016 Sep;26(5):463-72.

6 Chakravarthy H, Lin TK, Chen YL, Wu YM, Yeh CH, Wong HF. De novo formation of cerebral cavernous malformation adjacent to existing developmental venous anomaly: an effect of change in venous pressure associated with management of a complex dural arteriovenous fistula. Neuroradiol J. 2016;29(6): $458-64$.

7 Maeder P, Gudinchet F, Meuli R, de Tribolet N. Development of a cavernous malformation of the brain. AJNR Am J Neuroradiol. 1998; 19(6):1141-3.

8 Riant F, Bergametti F, Ayrignac X, Boulday G, Tournier-Lasserve E. Recent insights into cerebral cavernous malformations: the molecular genetics of CCM. FEBS J. 2010;277(5): $1070-5$.

9 Akers A, Al-Shahi Salman R, A Awad I, A Awad I, Flemming K, Hart B, et al. Synopsis of guidelines for the clinical management of cerebral cavernous malformations: consensus recommendations based on systematic literature review by the angioma alliance scientific advisory board clinical experts panel. Neurosurgery. 2017;80(5):665-80.

10 Dalyai RT, Ghobrial G, Awad I, Tjoumakaris S, Gonzalez LF, Dumont AS, et al. Management of incidental cavernous malformations: a review. Neurosurg Focus. 2011 Dec;31(6): E5.

11 Zafar A, Quadri SA, Farooqui M, Ikram A, Robinson M, Hart BL, et al. Familial cerebral cavernous malformations. Stroke. 2019 May; 50(5):1294-301.
12 Cornelius JF, Kürten K, Fischer I, Hänggi D, Steiger HJ. Quality of life after surgery for cerebral cavernoma: brainstem versus nonbrainstem location. World Neurosurg. 2016 Nov;95:315-21.

13 Flemming KD, Graff-Radford J, Aakre J, Kantarci K, Lanzino G, Brown RD, et al. Population-based prevalence of cerebral cavernous malformations in older adults: mayo clinic study of aging. JAMA Neurol. 2017;74(7): 801-5.

14 Spiegler S, Rath M, Paperlein C, Felbor U. Cerebral cavernous malformations: an update on prevalence, molecular genetic analyses, and genetic counselling. Mol Syndromol. 2018;9(2):60-9.

15 Rigamonti D, Hadley MN, Drayer BP, Johnson PC, Hoenig-Rigamonti K, Knight JT, et al. Cerebral cavernous malformations. Incidence and familial occurrence. N Engl J Med. 1988;319(6):343-7.

16 Zabramski JM, Wascher TM, Spetzler RF, Johnson B, Golfinos J, Drayer BP, et al. The natural history of familial cavernous malformations: results of an ongoing study. J Neurosurg. 1994;80(3):422-32.

17 Josephson CB, Rosenow F, Al-Shahi Salman R. Intracranial vascular malformations and epilepsy. Semin Neurol. 2015 Jun;35(3):22334.

18 Clatterbuck RE, Eberhart CG, Crain BJ, Rigamonti D. Ultrastructural and immunocytochemical evidence that an incompetent blood-brain barrier is related to the pathophysiology of cavernous malformations. J Neurol Neurosurg Psychiatry. 2001 Aug; 71(2):188-92.

19 Beechar VB, Srinivasan VM, Reznik OE, Sen A, Klisch TJ, Ropper AE, et al. Intraventricular cavernomas of the third ventricle: report of 2 cases and a systematic review of the literature. World Neurosurg. 2017 Sep;105: 935-43.e3.

20 Gross BA, Lin N, Du R, Day AL. The natural history of intracranial cavernous malformations. Neurosurg Focus. 2011;30(6):E24.

21 Expert Panel on Neurologic Imaging; Salmela MB, Salmela MB, Mortazavi S, Jagadeesan $\mathrm{BD}$, Broderick DF, Burns J, et al. ACR appropriateness criteria. J Am Coll Radiol. 2017; 14(5S):S34-61.

22 Flemming KD, Link MJ, Christianson TJ, Brown RD. Prospective hemorrhage risk of intracerebral cavernous malformations. Neurology 2012;78(9):632-6.
23 Al-Shahi Salman R, Hall JM, Horne MA Moultrie F, Josephson CB, Bhattacharya JJ; Scottish Audit of Intracranial Vascular Malformations (SAIVMs) Collaborators. Untreated clinical course of cerebral cavernous malformations: a prospective, populationbased cohort study. Lancet Neurol. 2012; 11(3):217-24.

24 Gross BA, Du R. Cerebral cavernous malformations: natural history and clinical management. Expert Rev Neurother. 2015;15: 771-7.

25 Takado Y, Minakawa T, Hadeishi H, Yoshida Y. A mass in the cerebellopontine angle presenting with subarachnoid haemorrhage. J Clin Neurosci. 2009;16:1051-117.

26 Liu XW, Wang SH, Chi ZF, Su LJ, Zhao XH, Wang SJ. The value of T (2) $\left({ }^{*}\right)$-weighted gradient echo imaging for detection of familial cerebral cavernous malformation: a study of two families. Exp Ther Med. 2013;5(2):44852.

27 Li D, Jiao YM, Wang L, Lin FX, Wu J, Tong $\mathrm{XZ}$, et al. Surgical outcome of motor deficits and neurological status in brainstem cavernous malformations based on preoperative diffusion tensor imaging: a prospective randomized clinical trial. J. Neurosurg. 2018 Mar 16; 130(1):286-301.

28 Horne MA, Flemming KD, Su IC, Stapf C, Jeon JP, Li D, et al. Clinical course of untreated cerebral cavernous malformations: a metaanalysis of individual patient data. Lancet Neurol. 2016 Feb;15(2):166-73.

29 Sze G, Krol G, Olsen WL, Harper PS, Galicich $\mathrm{JH}$, Heier LA, et al. Hemorrhagic neoplasms: MR mimics of occult vascular malformations. Am J Roentgenol. 1987;149(6):1223-30.

30 Cauley KA, Andrews T, Gonyea JV, Filippi CG. Magnetic resonance diffusion tensor imaging and tractography of intracranial cavernous malformations: preliminary observations and characterization of the hemosiderin rim. J Neurosurg. 2010;112(4):814-23.

31 Mouchtouris N, Chalouhi N, Chitale A, Starke RM, Tjoumakaris SI, Rosenwasser RH, et al. Management of cerebral cavernous malformations: from diagnosis to treatment. ScientificWorldJournal. 2015;68:808314.

32 de Champfleur NM, Langlois C, Ankenbrandt WJ, Le Bars E, Leroy MA, Duffau H, et al. Magnetic resonance imaging evaluation of cerebral cavernous malformations with susceptibility-weighted imaging. Neurosurgery. 2011;68(3):641-8. 
33 Barnes SR, Haacke EM. Susceptibilityweighted imaging: clinical angiographic applications. Magn Reson Imaging Clin N Am. 2009;17(1):47-61.

34 Pinker K, Stavrou I, Szomolanyi P, Hoeftberger R, Weber M, Stadlbauer Aet al. Improved preoperative evaluation of cerebral cavernomas by high-field, high-resolution susceptibility-weighted magnetic resonance imaging at 3 Tesla: comparison with standard $(1.5 \mathrm{~T})$ magnetic resonance imaging and correlation with histopathological findings: preliminary results. Invest Radiol. 2007;42(6):346-51.

35 de Souza JM, Domingues RC, Cruz LC Jr, Domingues FS, Iasbeck T, Gasparetto EL. Susceptibility-weighted imaging for the evaluation of patients with familial cerebral cavernous malformations: a comparison with T2-weighted fast spin-echo and gradientecho sequences. AJNR Am J Neuroradiol. 2008;29(1):154-8.

36 Campbell PG, Jabbour P, Yadla S, Awad IA. Emerging clinical imaging techniques for cerebral cavernous malformations: a systematic review. Neurosurg Focus. 2010;29(3):E6.

37 Moultrie F, Horne MA, Josephson CB, Hall JM, Counsell CE, Bhattacharya JJ, et al. Outcome after surgical or conservative management of cerebral cavernous malformations. Neurology. 2014;83:582-9.

38 Stapleton CJ, Barker FG 2nd. Cranial cavernous malformations: natural history and treatment. Stroke. 2018;49(4):1029-35.

39 Wang CC, Liu A, Zhang JT, Sun B, Zhao YL. Surgical management of brain-stem cavernous malformations: report of 137 cases. Surg Neurol. 2003;59(6):444-54.

40 Cenzato M, Stefini R, Ambrosi C, Giovanelli M. Post-operative remnants of brainstem cavernomas: incidence, risk factors and management. Acta Neurochir. 2008;150(9):87987.

41 Gralla J, Ganslandt O, Kober H, Buchfelder M, Fahlbusch R, Nimsky C. Image-guided removal of supratentorial cavernomas in critical brain areas: application of neuronavigation and intraoperative magnetic resonance imaging. Minim Invasive Neurosurg. 2003; 46(2):72-7.

42 Golden M, Saeidi S, Liem B, Marchand E, Morrison L, Hart B. Sensitivity of patients with familial cerebral cavernous malformations to therapeutic radiation. J Med Imaging Radiat Oncol. 2015;59(1):134-6.
43 Niranjan A, Lunsford LD. Stereotactic radiosurgery guidelines for the management of patients with intracranial cavernous malformations. Prog Neurol Surg. 2013;27:166-75.

44 Rosenow F, Alonso-Vanegas MA, Baumgartner C, Blümcke I, Carreño M, Gizewski ER, et al. Cavernoma-related epilepsy: review and recommendations for management: report of the Surgical Task Force of the ILAE Commission on Therapeutic Strategies. Epilepsia. 2013;54(12):2025-35.

45 Flemming KD, Link MJ, Christianson TJ, Brown RD Jr. Use of antithrombotic agents in patients with intracerebral cavernous malformations. J Neurosurg. 2013;118(1):43-6.

46 Schneble HM, Soumare A, Hervé D, Bresson D, Guichard JP, Riant F, et al. Antithrombotic therapy and bleeding risk in a prospective cohort study of patients with cerebral cavernous malformations. Stroke. 2012;43(12):3196-9.

47 Triquenot-Bagan A, Lebas A, Ozkul-Wermester O, Guégan-Massardier E, Lefaucheur R. Brain developmental venous anomaly thrombosis. Acta Neurol Belg. 2017 Mar; 117(1):315-6.

48 Amuluru K, Al-Mufti F, Hannaford S, Singh IP, Prestigiacomo CJ, Gandhi CD. Symptomatic infratentorial thrombosed developmental venous anomaly: case report and review of the literature. Interv Neurol. 2016;4(3-4):130-7.

49 Aoki R, Srivatanakul K. Developmental venous anomaly: benign or not benign. Neurol Med Chir. 2016;56(9):534-43.

50 Ruíz DS, Yilmaz H, Gailloud P. Cerebral developmental venous anomalies: current concepts. Ann Neurol. 2009 Sep;66(3):271-83.

51 Walsh M, Parmar H, Mukherji SK, Mamourian A. Developmental venous anomaly with symptomatic thrombosis of the draining vein. J Neurosurg. 2008;109:1119-22.

52 Gama RL, Nakayama M, Távora DG, Bomfim RC, Carneiro TC, Pimentel LH. Thrombosed developmental venous anomaly associated with cerebral venous infarct. Arq Neuropsiquiatr. 2008;66(3A):560-2.

53 Pereira VM, Geibprasert S, Krings T, Aurboonyawat $\mathrm{T}$, Ozanne A, Toulgoat $\mathrm{F}$, et al. Pathomechanisms of symptomatic developmental venous anomalies. Stroke. 2008; 39(12):3201-15.

54 Lee C, Pennington MA, Kenney CM 3rd. MR evaluation of developmental venous anomalies: medullary venous anatomy of venous angiomas. AJNR Am J Neuroradiol. 1996;17(1): $61-70$.
55 Parker BJ, Sabb BJ. Developmental venous anomaly complicated by cerebral venous infarction. Radiol Case Rep. 2015;2(4):48.

56 Peltier J, Toussaint P, Desenclos C, Le Gars D, Deramond $\mathrm{H}$. Cerebral venous angioma of the pons complicated by nonhemorrhagic infarction. Case report. J Neurosurg. 2004; 101(4):690-3.

57 San Millán Ruíz D, Delavelle J, Yilmaz $\mathrm{H}$, Gailloud P, Piovan E, Bertramello A, et al. Parenchymal abnormalities associated with developmental venous anomalies. Neuroradiology. 2007;49(12):987-95.

58 Wurm G, Schnizer M, Fellner FA. Cerebral cavernous malformations associated with venous anomalies: surgical considerations. Neurosurgery. 2005;57:42-58.

59 Cakirer S. De novo formation of a cavernous malformation of the brain in the presence of a developmental venous anomaly. Clin Radiol. 2003;58:251-6.

60 Campeau NG, Lane JI. De novo development of a lesion with the appearance of a cavernous malformation adjacent to an existing developmental venous anomaly. AJNR Am J Neuroradiol. 2005;26:156-9.

61 Wilson CB. Cryptic vascular malformations. Clin Neurosurg. 1992;38:49-84.

62 Abdulrauf SI, Kaynar MY, Awad IA. A comparison of the clinical profile of cavernous malformations with and without associated venous malformations. Neurosurgery. 1999; 44(1):41-7.

63 Abe T, Singer RJ, Marks MP, Norbash AM, Crowley RS, Steinberg GK. Coexistence of occult vascular malformations and developmental venous anomalies in the central nervous system: MR evaluation. AJNR Am J Neuroradiol. 1998 Jan;19(1):51-7.

64 Sehgal V, Delproposto Z, Haacke EM, Tong KA, Wycliffe N, Kido DK, et al. Clinical applications of neuroimaging with susceptibility-weighted imaging. J Magn Reson Imaging. 2005;22(4):439-50.

65 Das KK, Rangari K, Singh S, Bhaisora KS, Jaiswal AK, Behari S. Coexistent cerebral cavernous malformation and developmental venous anomaly: does an aggressive natural history always call for surgical intervention? Asian J Neurosurg. 2019;14(1):31821.

Idiculla/Gurala/Philipose/Rajdev/

Patibandla 